\title{
Histoplasmose cutânea em gato: relato de caso
}

[Cutaneous histoplasmosis in cat: a case report]

\author{
R.A. Carneiro ${ }^{1}$, G.E. Lavalle $^{2}$, R.B. Araújo ${ }^{1}$ \\ ${ }^{1}$ Escola de Veterinária da UFMG \\ Caixa Postal 567 \\ 30123-970 - Belo Horizonte, MG \\ ${ }^{2}$ Hospital Veterinário da UFMG
}

\begin{abstract}
RESUMO
Descreve-se um caso de histoplasmose cutânea em um gato, da raça Siamesa, com três anos de idade. O animal apresentava crescimento de aspecto esponjoso, sangüinolento, com secreção purulenta na região nasal, cuja evolução ocorreu em cerca de dois meses. O exame citológico revelou presença de Histoplasma capsulatum. O animal foi tratado com cetoconazol durante 20 dias, ocorrendo remissão completa dos sintomas.
\end{abstract}

Palavras-chave: gato, histoplasmose, citologia

\begin{abstract}
A case of a cutenous histoplasmosis in a three-year-old male Siamese cat is described. The diagnosis was based on clinical signs and laboratory exams. Dramatic remission of clinical signs was observed with cetoconazol therapy.
\end{abstract}

Keywords: cat, histoplasmosis, cytology

\section{INTRODUÇÃO}

Histoplasmose é infecção micótica sistêmica causada por Histoplasma capsulatum, normalmente presente no solo e, mais freqüentemente, em terrenos contaminados por excrementos de pássaros e morcegos, havendo concretas possibilidades de contaminação humana (Wolf e Troy, 1995; Nelson e Couto, 2001). Também denominada doença de Darling (Guida, 1999), é considerada zoonose pela Organização Mundial de Saúde. $\mathrm{Na}$ espécie humana podem aparecer sintomas pulmonares com linfadenopatia, mas a transmissão zoonótica direta de animais infectados é improvável, visto que a fase leveduriforme não é tão infecciosa quanto a fase micelial (Nelson e Couto, 2001; Severo et al., 2001).
H. capsulatum é usualmente infectante de pulmões e é contraído via inalação de microconídias. Depois de um período de incubação de 12 a 16 dias, essas estruturas convertem-se em forma infectante nos pulmões e são fagocitadas pelos macrófagos, incumbindose esses da disseminação sistêmica, através de linfonodos regionais (Tyler et al. 1993; Kerl, 2003). Em determinadas situações, pode ocorrer disseminação linfoemática secundária que se traduz em lesões viscerais no fígado, no cérebro e nos rins, nas articulações e na pele (Guida, 1999). Clinicamente, os sintomas dependem dos órgãos acometidos. $\mathrm{Na}$ forma sistêmica, os animais podem apresentar febre, anorexia, depressão, perda de peso, diarréia, pneumonia granulomatosa com tosse crônica e dispnéia, granulomas generalizados, hepatomegalia e

Recebido para publicação em 13 de fevereiro de 2004

Recebido para publicação, após modificações, em 19 de agosto de 2004

E-mail: carneiro@vet.ufmg.br 
linfadenopatia. As lesões ósseas, cutâneas e oculares são menos freqüentes (Wolf e Troy, 1995; Kerl, 2003).

O diagnóstico da histoplasmose baseia-se em exames histopatológicos, sorológicos e testes alérgicos, porém o diagnóstico definitivo é feito mediante cultura (Severo et al., 2001). De acordo com Kerl (2003), o diagnóstico definitivo pode ser estabelecido por citologia ou histopatologia, que podem ser realizadas com material obtido via lavado traqueal, mielograma, citologia óssea e esfregaço retal. Os exames sorológicos não são confiáveis, pois podem apresentar resultados falso-negativos ou falso-positivos. Pode-se fazer ainda punção aspirativa do baço e do parênquima renal com agulha fina (Cowell e Tyler, 1993). No quadro sistêmico, os animais podem apresentar anemia normocítica e normocrômica não regenerativa, devido à infecção medular pelo parasita, causando diminuição da função medular normal, processo inflamatório crônico suprimindo a eritropoiese, e hemorragias gastrintestinais. Pode ocorrer trombocitopenia devido à coagulação intravascular disseminada (CID) ou destruição microangiopática e pancitopenia por afecção medular (Nelson e Couto, 2001). Alterações bioquímicas como azotemia, hipoproteinemia, aumento de fosfatase alcalina, hiperbilirrubinemia e hiperglobulinemia podem ser observadas (Wolf e Troy, 1995). Os gatos infectados podem apresentar-se clinicamente sadios ou desenvolver doença disseminada. A maioria dos casos ocorre em animais com menos de quatro anos de idade (Nelson e Couto, 2001).

Este trabalho teve por objetivo relatar um caso de histoplasmose cutânea em gato.

\section{CASUÍSTICA}

Foi atendido no Hospital Veterinário da UFMG um gato da raça Siamesa, com três anos de idade, apresentando na região nasal aumento de volume de aspecto esponjoso, consistência flutuante, sangrante e com secreção purulenta. Esses sinais apareceram há cerca de dois meses, e mostraramse resistentes ao tratamento com enrofloxacina, na dose de $5 \mathrm{mg} / \mathrm{kg}$ de peso (Fig. 1).

O animal apresentava-se ligeiramente desidratado, sem linfadenopatia, e respirava com relativo esforço. Devido à dificuldade respiratória, foram realizadas radiografias torácicas e dos seios nasais, nas posições laterolateral e ventrodorsal. Procedeu-se também à coleta de sangue para realização de hemograma. Suspeitando-se de neoplasia ou esporotricose, procedeu-se ao exame citológico (in print) da lesão (Cowell e Tyler, 1993), sendo o material devidamente fixado e corado pelos corantes de May Grunmwald-Giemsa, segundo técnica descrita por Lima et al. (2001) (Fig. 2).

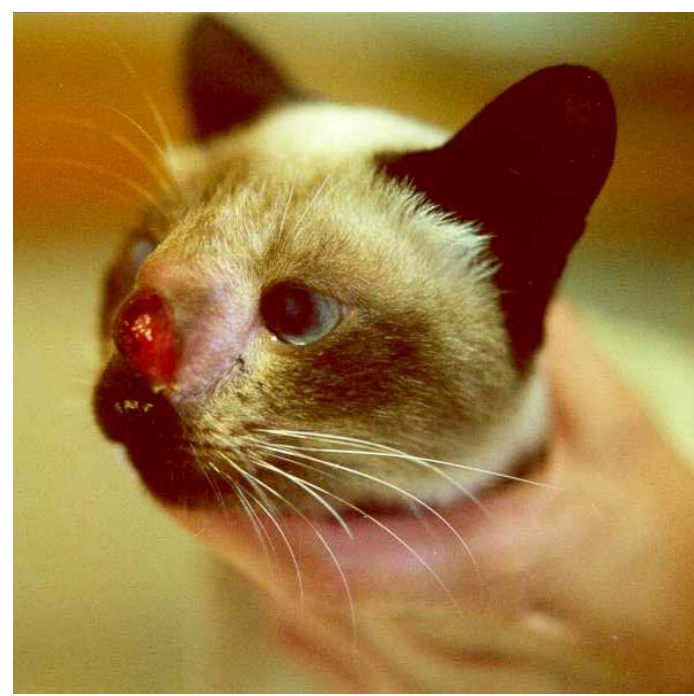

Figura 1. Gato Siamês apresentando lesão nasal de aspecto esponjoso, com áreas de inflamação.

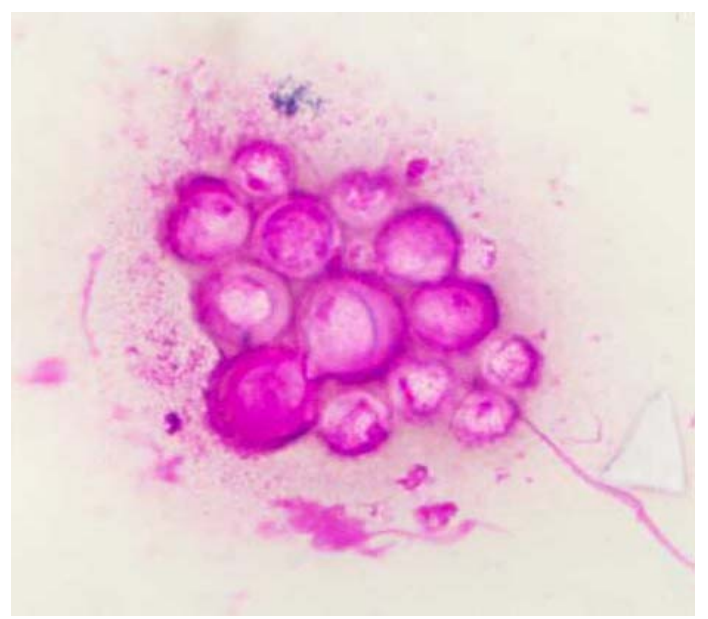

Figura 2. Exame citológico de lesão cutânea facial de um gato da raça Siamesa de três anos de idade. Formas de Histoplasma capsulatum. Coloração May Grunmwald-Giemsa. 1000×. 
O animal foi tratado com cetoconazol oral, manipulado na dose de $10 \mathrm{mg} / \mathrm{kg}$ de peso de 12 em 12 horas durante 15 dias, de acordo com protocolo terapêutico sugerido por Noxon et al. (1982), Wolf e Troy (1995) e Kerl (2003). O tratamento foi continuado por mais 10 dias, mantendo-se apenas uma dose diária de $10 \mathrm{mg} / \mathrm{kg}$. Além do tratamento oral, foi prescrito tratamento com cetoconazol tópico pelo mesmo período.

\section{DISCUSSÃO}

O estado geral do animal deveu-se, principalmente, à dificuldade de se alimentar e respirar, por isso os exames radiológicos foram realizados levando-se em conta a predileção dos parasitas pelos pulmões. Não foram observados nódulos pulmonares visíveis à radiografia, conforme descreveram Cutsem e Rochete (1991). Esses sinais justificam a dificuldade respiratória por obstrução externa nasal, conseqüência da lesão ulcerativa esponjosa.

O perfil hematológico mostrou-se dentro dos parâmetros normais. As alterações resumiram-se em eosinofilia, que ocorre, de acordo com Jain (1993), principalmente em conseqüência de lesões cutâneas ulcerativas (Tab. 1).

Tabela 1. Hemograma de um gato da raça Siamesa, três anos de idade, com diagnóstico de histoplasmose cutânea

\begin{tabular}{lc}
\hline Eritrograma & \\
\hline Eritrócitos $\left(\mathrm{x} 10^{6} / \mu \mathrm{l}\right)$ & 7.9 \\
Hemoglobina $(\mathrm{g} / \mathrm{dl})$ & 12,5 \\
Volume globular $(\%)$ & 36 \\
VGM $(\mathrm{fl})$ & 45 \\
CHGM $(\mathrm{g} / \mathrm{dl})$ & 34 \\
\hline Leucograma & Normocíticos e \\
\hline Leucócitos totais $(/ \mu \mathrm{l})$ & normocrômicos \\
Mielócitos $(/ \mu \mathrm{l})$ & 14.300 \\
Metamielócitos $(/ \mu \mathrm{l})$ & 0 \\
Neutrófilos bastonetes $(/ \mu \mathrm{l})$ & 0 \\
Neutrófilos segmentados $(/ \mu \mathrm{l})$ & 200 \\
Linfócitos $(/ \mu \mathrm{l})$ & 8.100 \\
Monócitos $(/ \mu \mathrm{l})$ & 3.300 \\
Eosinófilos $(/ \mu \mathrm{l})$ & 500 \\
Basófilos $(/ \mu \mathrm{l})$ & 2200 \\
Estimativa de plaquetas $(\mu \mathrm{l})$ & 0 \\
\hline Proteínas totais $(\mathrm{g} / \mathrm{dl})$ & 220.000 \\
\hline VGM = volume globular médio; CHGM = concentração de \\
hemoglobina globular média.
\end{tabular}

No exame citológico, foram observadas formas redondas, com poucas formas ovais, em geral pequenas, com cerca de metade à quarta parte do tamanho de uma hemácia, de coloração discretamente azulada, compatíveis com formas de $H$. capsulatum. (Fig. 2). Essas estruturas foram observadas tanto intra como extracelular aos macrófagos, e não foram observadas formas intraneutrofílicas já descritas por Tyler et al. (1993).

Como o diagnóstico definitivo foi realizado com segurança pela citologia por aposição, segundo Kerl (2003) e Shelly (2003), e tendo em vista que o exame citológico é, de acordo com Tyler et al. (1993) e Kerl (2003), definitivo para confirmação da doença, não houve necessidade de exames histológicos. Lesões cutâneas semelhantes podem ser causadas por Sporotrix schenkii, ou neoplasias como granuloma eosinofílico felino ou carcinoma espinocelular. $\mathrm{O}$ diagnóstico diferencial é realizado principalmente por citologia por aposição ou "in print" (Tyler et al., 1993). Segundo esses autores, Sporotrix tem forma fusiforme clássica, que difere da forma oval do $H$. capsulatum. A predominância de eosinófilos na lesão caracteriza o granuloma eosinofílico, e o carcinoma espinocelular apresenta células neoplásicas características.

Segundo Cutsem e Rochete (1991), algumas micoses, como a aspergilose, causadas por fungos do gênero Aspergillus, presentes na cavidade nasal, podem apresentar lesões semelhantes, que tendem a causar rinites com descargas nasais e espirros. Contudo, as radiografias dos seios não mostraram lesões aparentes.

A escolha do tratamento com cetoconazol deveuse à inexistência de quadro sistêmico, comprovado por exames laboratoriais e radiográficos. Outros medicamentos antifúngicos, como anfotericina B (Kerl, 2003; Grooters e Taboada, 2003) e itraconazol (Kerl, 2003; Grooters e Taboada, 2003), são indicados para o tratamento de histoplasmose sistêmica, mas, devido à ação altamente nefrotóxica do primeiro (Plumb, 1991) e ao elevado custo do segundo, optou-se pelo uso do cetoconazol, preconizado por Plumb (1991), Fernandes et al. (2003) e Grooters e Taboada (2003). A grande fonte de contaminação, segundo Cury et al. 
(2001), são os locais habitados por morcegos e aves. Neste caso, como o animal teve acesso irrestrito à rua, não foi possível defini-los.

\section{CONCLUSÕES}

O relato de histoplasmose cutânea em um gato permite concluir que o exame citológico é fundamental para o diagnóstico, e o tratamento com cetoconazol é eficiente, permitindo completa remissão das lesões e restabelecimento de condições clínicas satisfatórias.

\section{REFERÊNCIAS BIBLIOGRÁFICAS}

COWELL, R.L.; TYLER, R.D. Diagnostic cytologic of the dog and cat. California: American Veterinary Publications, 1993.

CURY, G.C.; DINIZ FILHO, A.; COSTA E CRUZ, A.C.; et al. Surto de histoplasmose em Pedro Leopoldo, Minas Gerais, Brasil. Rev. Soc. Bras. Med. Trop., v.34, p.483-486, 2001.

CUTSEM, J.V.; ROCHETE, F. Mycoses in domestic animals. Janssen Research Foundation, 1991. 226p.

FERNANDES, C.G.N.; MOURA, S. T.; AVILA, $M$. et al. Canine histoplasmosis in the urban area of Cuiaba, Mato Grosso. Case report. Clin. Vet., n. 46, p.44-46, 2003

GROOTERS, A.M.; TABOADA, J. Update on antifungal therapy. Vet. North Am.: Small Anim. Pract., v.33, p.749-758, 2003.

GUIDA, N. Contribuición al conocimiento de la histoplasmosis, cooccidiomicosis, y aspergilosis aviar, em animais domésticos de la República Argentina. Rev. Arg. Micol., v.22, p.4-28, 1999.
JAIN, N.C. Essentials of veterinary hematology: Philadelphia: Lea \& Febiger, 1993. 417p.

KERL, M.E. Update on canine and feline fungal diseases. Vet. North Am.: Small Animal Pract., v.33, p.721-747, 2003.

LIMA, A.O.; SOARES, J.B.; GRECO, J.B. et al. Métodos de laboratório aplicados à clínica: técnica e interpretação. 8.ed. Rio de Janeiro: Guanabara Koogan, 2001. 1200p.

NELSON, R. W.; COUTO, C. G. Medicina interna de pequenos animais. 2.ed. Rio de Janeiro: Guanabara Koogan, 2001. 1084p.

NOXON, J.O; DIGILIO, K.; SCHIMIDT, D.A. Disseminated Histoplasmosis in a cat: successful treatment with ketoconazole. J. Am. Vet. Med. Assoc., v.181, p.817-820, 1982.

PLUMB, D.C. Veterinary drug handbook. White Bear Lake: Phama Vet., 1991. 688p.

SEVERO, L.C.; OLIVEIRA, F.M.; IRION, K. et al. Histoplasmosis in Rio Grande do Sul, Brazil: a 21 year experience. Rev. Inst. Med. Trop. São Paulo., v.43, p.183-187, 2001.

SHELLY, S.M. Cutaneous lesions. Vet. North Am.: Small Anim. Pract., v.33, p.1-46. 2003.

TYLER, R.D.; COWELL, R.L.; MEINKOTH, J. H. Cutaneous and Subcutaneous lesions: masses, cysts, ulcers and fistulous tracts. IN: COWEL, R.L.; TYLER, R.D. Diagnostic cytologic of the dog and cat. California: American Veterinary Publications, 1993. p.21-46

WOLF, A.M.; TROY, G.C. Deep mycotic diseases. In: ETTINGER, S.J.; FELDMAN, E.C. Text book of veterinary internal medicine: diseases of the dog and cat. 4.ed. Philadelphia: W.B. Saunders, 1995. p.439 - 463. 